\title{
АВТОМАТИЧЕСКОЕ РЕГУЛИРОВАНИЕ ПРОЦЕССА ГОРЕНИЯ В АЭРОФОНТАННОЙ ТОПКЕ
}

\author{
Э. КЮННАП, \\ tehnikateaduste kandidaat
}

\begin{abstract}
Одним из важнейших узлов установки термической переработки мелкого сланца твердым теплоносителем ['] является аэрофонтанная топка. Там происходит выжигание полукокса, выходящего из реактора. Посте прохождения аэрофонтанной топки юолукокс превращается в твердый теплоноситель, часть которого подается обратно в реактор.
\end{abstract}

Процесс горения в аэрофонтанной топке в данной установке происходит при значении коэффициента избытка воздуха меньше единицы. Регулятором. воздуха был выбран электронный регулятор ЭР-Т, выпускаемый заводом «Энергоприбор». Первичным прибором для регулятора была термопара TXA-VIII. Опыты регулирования процесса горения в аэрофонтанной топке показали, что если полукокс, выходящий из реактора, подается в аэрофонтанную топку равномерно, то регулирование процесса горения в аэрофонтанной топке по температуре уходящих из нее дымовых газов изменением расхода воздуха происходит удовлетворительно. Если же количество или капество полукокса, подаваемого в аэрофонтанную топку, резко меняется, то такое регулирование не устойчиво.

Поскольку регулятор воздуха настраивается на значение коэффициента избытка воздуха в аэрофонтанной топке ниже единицы, то при постоянном значении количества воздуха и измененном значении подачи количества органики, подаваемого полукоксом в аэрофонтанную. топку, значение коэффициента избытка воздуха стихийно изменяется, т. е. может стать и больше единицы. При нормальной настройке для повышения температуры в аэрофонтанной топке регулятор увеличивает расход воздуха, а для понижения температуры уменьшает его. Но если коэффициент избытка воздуха станет больше единицы, то регулятор будет работать неправильно, так как при увеличении количества воздуха температура газов будет еще падать, а при уменьшении повышаться.

При регулировании температуры аэрофонтанной топки необходимо учитывать еще другое обстоятельство.

Исходя из условия нормального прохождения технологического процесса в аэрофонтанной топке, количество воздуха должно соответствовать количеству поступаюшего туда же полукокса в такой мере, чтобы было еще обеспечено поддерживание полукокса во взвешенном состоянии. При нарушении этого условия начинается пульсация полукокса вдоль аэрофонтанной топки, т. е. при малом расходе он накапливается на дне топки, препятствуя проходу воздуха. Вследствие этого давление воздуха под слоем полукокса повышается, и если оно достигает определенной величины, то слой полукокса подбрасывается вверх, давление воздуха падает, полукокс опять накапливается на дне топки, и так процесс периодически повторяется.

Для предотвращения такого явления необходимо не допускать уменьшения расхода воздуха ниже определенной величины. Очевидно, соответствующий импульс для 
регулятора или какого-ннбудь другого устройства необходимо взять по расходу воздуха. Если регулятор воздуха при стабилизации температуры газов, уходящих из аэрофонтанной топки, уменьшает расход воздуха ниже определенной величины (это происходит при увеличении количества органики в полукоксе вследствие неполной термической переработки сухого сланца в реакторе), устанавливаемой опытным путем, то специальная установка (или сам регулятор) должна увеличивать его до стабилизации давления воздуха, подаваемого в аэрофонтанную топку. При этом регулятор воздуха должен быть в отключенном положении, ибо при увеличении расхода воздуха по давлению его температура газов повышается. Вследствии этого регулятор должен уменьшить расход воздуха, т. е. он выведет топку обратно в нестабильное состояние по давлению воздуха.

При стабилизации температуры газов, отходящих из аэрофонтанной топки, может возникнуть, с другой стороны, такое положение, что при резком уменьшении расхода полукокса, подаваемого в аэрофонтанную топку, или понижение его качества (уменьшение колнчества органики в полукоксе) и переходе процесса горения на область коэффициента избытка воздуха больше единицы, регулятор вместо необходимого уменьшения воздуха прибавляет его. Процесс горения переносится за пределы аэрофонтанной топки и продолжается в ее дымовом канале. Для исследования процесса горения в аэрофонтанной топке и регулирования его в разных местах на пути газового тракта были установлены термопары (9-я, 10-я и 11-я точки измерения). Регулирование процесса горения термопарой, расположенной в верхней части аэрофонтанной топки (9-я точка измерения), не дало удовлетворитєльных результатов, хотя теоретически процесс горения должен был закончиться в конце топки. Лучшие результаты дало регулирование процесса горения при помощи термопары, установленной уже в дымовом канале (10-я точка измерения). Очевидно, максимальная температура уходящих из аэрофонтанной топки газов при нормальном соответствии расходов полукокса номинального качества и воздуха находится где-то в области 10-й точки измерения, причем тогда температура газов в 11 -й точке измерения на $100 \div$ $\div 110^{\circ} \mathrm{C}$ ниже, чем в 10 -й точке.

Если же по причинам, приведенным выше, процесс горения начинает проходить при значении коэффициента избытка воздуха больше единицы и регулятор воздуха для восстановления температуры газов вместо уменьшения расхода поступаюшего в аэрофонтанную топку воздуха его беспрерывно увеличивает, то процесс горения переносится дальше в дымовой канал и разность температуры газов между 10-й и 11-й точками измерения начинает уменьшаться. Таким образом, если процесс горения перейдет в область коэффициента избытка воздуха больше единицы (т. е. при увеличении расхода воздуха, температура газов не повышается за счет увеличения теплоты гореніяя, а понижается за счет смешения дымовых газов с холодным воздухом), то вследствие увеличения скорости смеси газов и воздуха, выходящей из аэрофонтанной топки, фронт горения переносится вглубь дымового канала, и поэтому разность температур в 10-й и 11-й точках измерения начинает уменьшаться.

Учитывая вышеуказанные обстоятельства к регулятору воздуха, необходимо еще прибавить устройства, которые в случае чрезмерного уменьшения и увеличения расхода воздуха привели бы его в норму, необходимую для нормальной работы аэрофонтанной топки, несмотря на то, что в эти моменты расход воздуха не соответствует номинальной температуре уходяших из нее газов.

Если поддерживание нижнего предела расхода воздуха, который в общем случае лвляется переменной величиной и зависит от нагрузки установки (т. е. расхода полукокса, поступающего в аэрофонтанную топку), колеблясь практически в пределах $3300 \div 3500 \mathrm{~m}^{3} / 4 a c$, которому соответствует разность давлений в измерительной трубке $50 \div 52$ мм в. ст. можно осуществить при помощи датчика, который реагирует на эту разность, то определение и, следовательно, поддержание верхнего предела расхода воздуха по ее расходу, не дает удовлетворительного результата. Верхний допустимый предел расхода воздуха не так четко выражен по сравнению с нижним пределом и может колебаться в более широком диапазоне в зависимости от нагрузки установки. 
Поэтому верхний допустимый предел расхода воздуха может быть лучше всего ограничен разностью температур по тракту уходящих из аэрофонтанной топки дымовых газов, т. е. разностью температур между 10-й и 11-й точками измерения. Если эта разность, величина которой определяется опытным путем, выдерживается, то одновременно отпадает опасность выдувания всего полукокса из аэрофонтанной топки. Таким образом, уменьшение разности температур ниже определенной величины показывает, что фронт горения переносится в дымовые каналы, процесс горения переходит в область коэффициента избытка воздуха больше единицы, и для ликвидации этого явления необходимо уменьшить количество поступающего в аэрофонтанную топку воздуха. При этом регулятор воздуха должен находиться в выключенном положении, так как в этом периоде регулирование количества воздуха не соответствует температуре газов. Регулятор воздуха должен находиться в выключенном положении также в случае чрезмерного уменьшения расхода воздуха, в периоде регулирования количества воздуха по его минимальному расходу, чтобы дать возможность стабилизировать температуру газов, которая резко изменяется вследствие резкого изменения расхода воздуха без регулятора температуры, и после этого снова включить его. Этот промежуток времени выбирается опытным путем и значительно облегчает работу регулятора воздуха.

Ртутное блокирующее устройство, изготовленное в Институте кибернетики АН ЭССР, по конструкции напоминает контактный термометр. Внутренний диаметр стеклянной трубки, где находится ртуть, состав.ля 4 мм. Внутрь трубки пропущено три контакта. Разность давлений воздуха передается в эту трубку, и ртутный столбик, высота которого пропорциональна расходу воздуха, через усилитель включает и выключает соответствующую электрическую цепь магнитного контактора регулятора воздуха.

Ртутное блокирующее устройство дало хорошие результаты при поддерживании нижнего предела расхода воздуха. Но отсутствие реле времени, которое поддерживало бы регулятор воздуха после изменения расхода воздуха в течение определенного про. межутка времени в выключенном состоянии, и ненадежная конструкция самого устройства не позволили рекомендовать его для применения в промышленной установке. Кроме того, оно не дало возможность ограничить верхний предел расхода воздуха.

Вместо ртутного блокирующего устройства было изготовлено электронное блокирующее устройство , более надежное по конструкции и позволяющее легко выби рать параметры для включения и выключения, а также времена задержки. Кроме того, Б этом устройстве учитывается изменение расхода сырого сланца, от которого, как было сказано выше, сильно зависит условие подачи воздуха в аэрофонтанную топку.

\section{Описание схемы блокирующего устройства}

Устройство (рис. 1) рассматривается по частям структурной схемы (рис. 2). Номера точек в схеме (рис. 1) соответствуют номерам точек на рис. 3.

1. Измерение разности температур на установке (точки 10 и 11) происходит в звене 4 (рис. 2), которое представляет собой последовательно включенные термопары, сопротивления и потенциометр. Соотношение этих температур в милливольтах (т. е. выбор разности температур, при которой начинает действовать блокирующее устройство) производится потенциометром $\Pi_{3}$ и передается в полярночувствительное устройство (поз. 5, рис. 2), состоящее из магнитного усилителя и двух ламп. Оно почти идентичное с применяемыми в электронных регуляторах типа ЭР-Т усилителями, но без каскада обратной связи.

* В Комитет по делам изобретений и открытий при Совете Министров СССР автором подаІіа заявка за № 816003/24-6 о получении авторского свидетельства. 

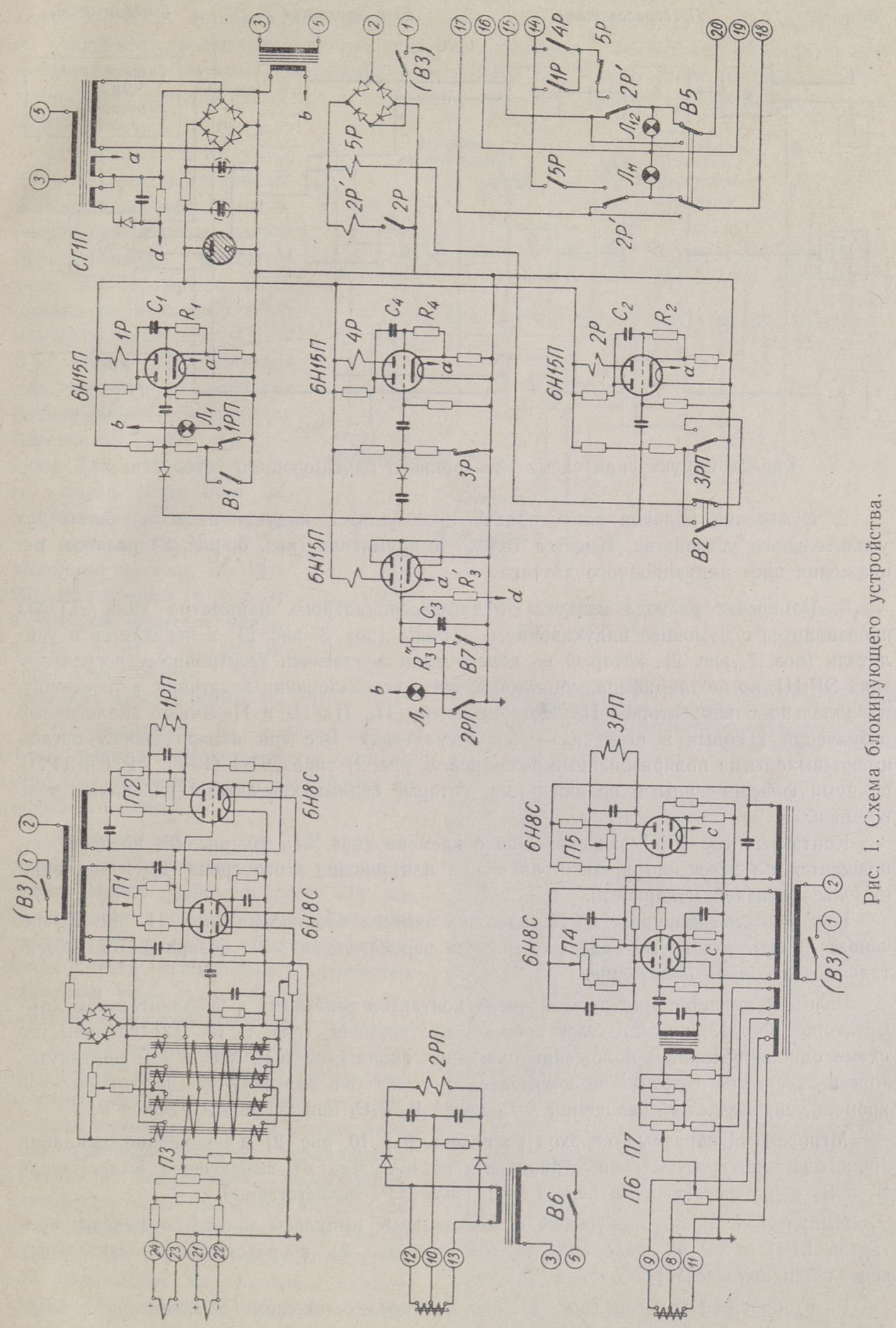


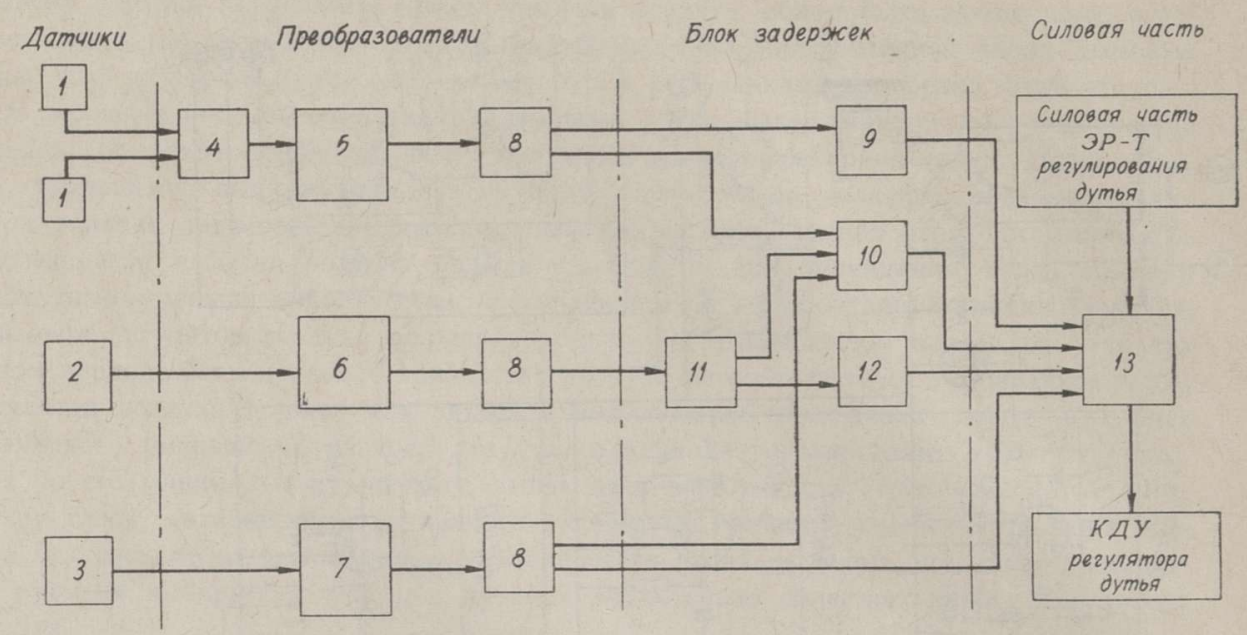

Рис. 2. Структурная схема электронного блокирующего устройства.

2. Измерение наличия сланцеподачи производится индукционным датчиком без усилительного устройства. Имеется только выпрямитель (поз. 6, рис. 2) разницы напряжения плеч индукционного датчика.

3. Измерение расхода воздуха от дифференциального манометра типа ДТ-200 производится с помощью индукционного датчика (поз. 3 , рис. 2 ), и передается в усилитель (поз. 7 , рис. 2), который по конструкции аналогичен электронному регулятору типа ЭР-III, но без демпфера, обратной связи и использования задатчика, включенного параллельно с корректором $\Pi_{7}$. Потенциометры $\Pi_{4}, \Pi_{5}, \Pi_{6}$ и $\Pi_{7}$ имеют аналогичные назначения таковых в вышеуказанных регуляторах. Все три измерительных органа имеют выходы на поляризованные реле (поз. 8, рис. 2) типа РП-4 (1 РП, 2 РП и 3 РП) с двумя фиксированными положениями, которые своими контактами управляют реле времени.

Контакты реле 1 РП запускают реле времени (поз. 9 и 10, рис. 2), которое возвращается по истечении времени задержки или раньше этого срока при получении импульсов разной полярности.

При срабатывании реле 3 РП задержки запуска блокировки (поз. 11, рис. 2) начинает вычитывать время задержки, но при переключении 3 РП возвращается моментально в исходное положение.

Реле 5 Р является множителем чиста контактов реле 3 РП в исполнительном коммутаторе (поз, 13, рис. 2). Электронные реле времени (поз. 9, 10, 12) собраны по схеме одновибратора. В положении ожидания якоря реле $1 \mathrm{P}, 2 \mathrm{P}$ и 4 Р притянуты. При поступлении импульса положительного знака они отпускаются на промежуток времени, определяемый величнной $R_{1} C_{1}$ при $1 \mathrm{P}, R_{2} C_{2}$ при $2 \mathrm{P}$ и $R_{4} C_{4}$ при $4 \mathrm{P}$.

Мгновенный обратный переход реле (поз. 9 и 10, рис. 2) в положение ожидания происходит при поступлении отрицательного импульса от выключения выключателя $\mathrm{B}_{1}$ и $\mathrm{B}_{2}$ или переключением реле $1 \mathrm{P}, 2 \mathrm{P}$ или $3 \mathrm{P}$ соответственно.

Импульсные линии пропускают положительные импульсы только со стороны контактов 1 РП и $3 \mathrm{P}$ на реле времени (поз. 10, рис. 2) посредством разделительных вентилей и конденсаторов.

Реле задержки запуска (пос. 11, рис. 2) собрано по схеме обыкновенного электронного реле времени. Задержка запуска осуществляется зарядкой конденсатора $C_{3}$ через сопротивление $R_{3}^{\prime}$. Кроме того имеется сравнительно большое разрядное со. противление $R^{\prime \prime}{ }_{3}$. Это уменьшает время задержки реле при частом срабатывании реле 2 РП, т. е. при изменении расхода сланца на короткий промежуток времени, 
который по продолжительности меньше времени срабатывания реле времени $3 \mathrm{P}$ (поз. 11 , рис. 2). В положении ожидания якорь реле 3 Р притянут, при срабатывании он отпускается, и возвращение в положение ожидания производится разрядкой конденсатора $C_{3}$, обратным переключением реле 2 РП или выключением выключателя $B_{7}$. Напряжение зарядки снимается с добавочной обмотки трансформатора питания блокд задержки.

Выходной коммутатор (поз. 13, рис. 2) производит блокирование выходящих из регулятора воздуха команд переключением контактов реле $2 \mathrm{P}^{\prime}$ и подачи своих команд на контактор через контақты реле $1 \mathrm{P}, 4 \mathrm{P}$ и $5 \mathrm{P}$, кроме $2 \mathrm{P}^{\prime}$. Питание для командных сигналов блокирующего устройства берется из регулятора воздуха. Для этой цели нмеется, кроме соединения на магнитный контактор (входные клеммы 15,16 и 17 н выходные клеммы 18, 19 и 20), еще клемма 14 (рис. 3), к которой подается напряжение - 24 в от регуля тора (напряжение +24 6 проходит через клеммы 16, 19)

Выключателем $\mathrm{B}_{5}$ можно выключить действие блокирующего устройства для проверки всего устройства во время его работы.

Вспомогательное реле $2 \mathrm{P}$ используется для предотвращения ложного блокирующего действия реле $2 \mathrm{P}$, которое имеет в ожидающем положении притянутый якорь, и в случае отключения питания блокирующее устройство отпускает свой якорь и включает магнитный контактор через реле $5 \mathrm{P}$.

Испытание действия блокирующего устройства дало хорошие результать, особенно при замене обычных промышленных термопар большой инерционности малоинерцнонными термопарами. Описанное электронное блокирующее устройство было настроено на следующие величины: разность температур между 10-й и 11-й точками, при которой включается блокирующее устройство, - $60^{\circ}$; время выключения регулятора температуры и одновременное включение регулирующего органа для уменьшения расхода воздуха - 11 сек; время задержки регулятора в выключен-

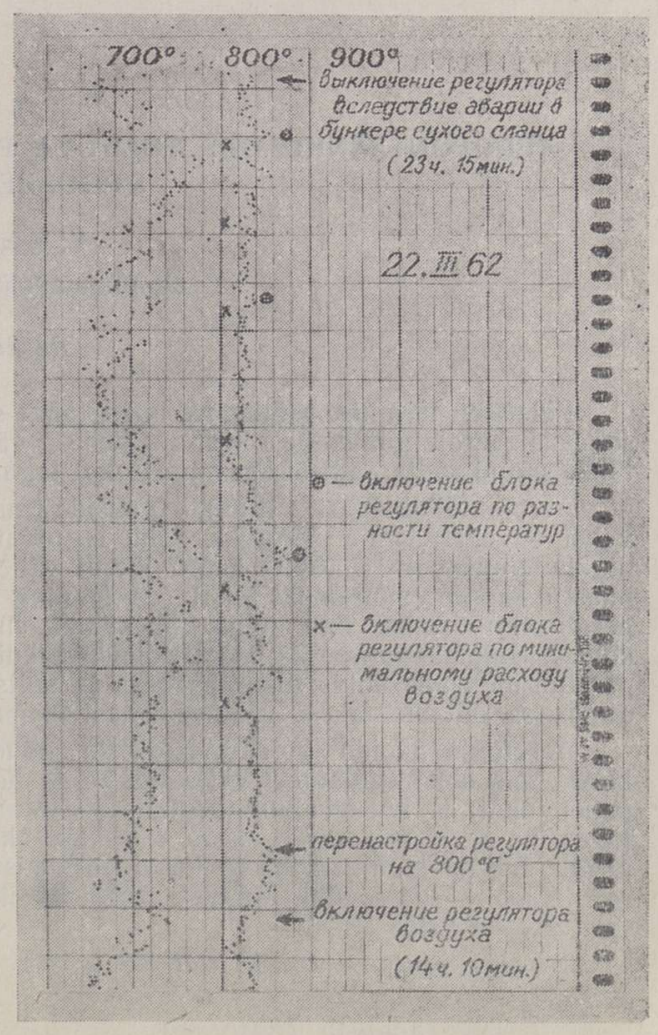

P!!C. 4.

5 ENSV TA Toimetised T-2 63 
ном положении - 22 сек; минимальный расход воздуха, при котором включается блоки -

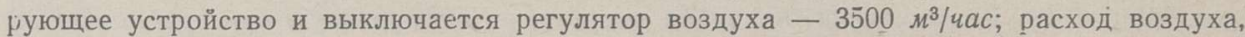
при котором происходит обратное действие, т. е. выключение блокирующего устройства и включение регулятора воздуха, - $3550 \mathrm{~m}^{3} /$ час. Импульс по расходу сланца не был использован.

Измерение температуры производилось при помощи малоинерционных хромельалумель термопар, изготовленных из проволоки диаметром 1,2 мм. Защитная трубка из жароупорной стали имела внутренний диаметр 8 мм.

Қак показала эксплуатация блокирующего устройства, регулирование температуры стабилизировалось в довольно узкие пределы, за исключением момента выключения регулятора блокирующим устройством (рис. 4).

Описанное электронное блокирующее устройство может быть также использовано при автоматическом регулировании процесса горения во всех других с аналогичными техническими требованиями аэрофонтанных топках.

\title{
Л И Т Е Р А Т У Р А
}

1. Э. Ю. К н н а п, Автоматическое управление установки термической переработки сланца твердым теплоносителем при помощи экстремального регулятора. Изв. AH ЭССР, 10, 4, 1961.

\author{
Институт кибернетики \\ Академии наук Эстонской ССР
}

Поступила в редакцию

3. IV 1962

\section{AEROFONTÄÃNKOLDES TOIMUVA PÖLEMISPROTSESSI AUTOMAATNE REGULEERIMINE}

\author{
E. Künnap, \\ tehnikateaduste kandidaat
}

\section{Resümee}

Põlevkivi termilise töötlemise uues, tahke soojakandjaga seadmes on üheks tähtsamaks sõlmeks aerofontäänkolle, kus reaktorist väljuva poolkoksi pōlemise tagajärjel tekib tahke soojakandja, millest osa suunatakse tagasi reaktorisse.

Aerofontäänkoldest väljuvate gaaside temperatuuri ja koldesse antava õhu hulga vahel on ekstreemne sōltuvus. Ohu regulaator on justeeritud piirkonnale, mis vastab liigōhutegurile $\alpha<1$. Koksi hulga järsul vähenemisel või tema kvaliteedi järsul halvenemisel $\alpha$ muutub suuremaks kui $1(\alpha>1)$ ning hakkab töötama valesti: selle asemel et temperatuuri tõusmisel õhu hulka vähendada, suurendab ta seda ning põlemisfront kandub koldest suitsukanalisse ja isegi pōlevkivi kuivatisse. Viimast asjaolu iseloomustab temperatuuride vahe kolde ülemises osas ja suitsukanali valitud punktis: põlemisfrondi kandumisega suitsukanalisse väheneb gaasi temperatuuride vahe nendes punktides.

Aerofontäänkolde aerodünaamiliste nõudmiste rahuldamiseks valmistati elektronblokk, mis ôhu regulaatori välja lülitab ja hoiab ta selles olekus valitud ajaühiku vältel kahel juhul: 1) kui õhu hulk regulaatori toimel liigselt suureneb, s. t. põlemisprotsess on kaldunud piirkonda $\alpha>1$, ja 2) kui koksi hea kvaliteedi puhul ōhu hulk vähendatakse piirini, mis ei kindlusta enam koksi hõljumist aerofontäänkoldes. Alumine piiraja töötab induktsioon-tajuriga õhu hulgast, ülemine piir termopaariga temperatuuride vahest mõõdetavate punktide vahel.

Katsetulemused näitasid, et blokk täidab temale pandud ülesande täiesti rahuldavalt. 


\section{AUTOMATIC CONTROL OF COMBUSTION PROCESS IN AN AIR FOUNTAIN FURNACE}

\section{E. Künnap}

\section{Summary}

In the equipment for the thermal treatment of oil shale with a solid heat-carrier, a most important detail is the air fountain furnace.

An electronical blocking equipment acting with an air controller is described. The minimum amount of air is limited by the aerodynamical properties of the furnace, the maximum one - by the difference of degrees of the temperature measured at the top of the furnace and in the smoke-channel. In both cases, the air controller is turned off by the blocking equipment and kept in this position till a stabilization of the temperature is obtained.

Academy of Sciences of the Estonian S.S.R., Received Institute of Cybernetics 